\title{
Book Review: International Assistance and State-University Relations
}

\author{
By Jo Bastiaens \\ London: Routledge, 2008. 260 pp. \\ ISBN: 978-04-159-9074-5
}

International Assistance in developing countries comes in many forms, all with intended outcomes and agency objectives. Countries receiving donor aid, or large loans from multinational agencies, face the daunting task of exploring ways to incorporate donor objectives with local needs. In addition, the impact of aid from foreign sources creates an additional element of consideration, as receiving entities must meet the needs of the donor agency, the projects receiving funding, as well as various stakeholders with a vested interest in the programs receiving funding. International Assistance and State-University Relations explores the relationships between international organizations and universities controlled by a state-centered education system in Indonesia.

The nuances of these relationships are affected by a variety of factors that lead to increasingly complex relationships between states, universities, and nongovernmental organizations (NGOs). This case study explores these relationships in Indonesia from the perspective of two large NGOs, one that is internationally funded and one that is supported by a foreign government. Research explores the explicit and implicit goals of the respective NGOs, and how those goals correspond with relationships between the state and the university regarding decision-making, financing, and the changing patterns in relationships seen in Indonesian higher education. The interconnectedness of these factors affecting the educational framework is explored.

In International Assistance and State-University Relations, Jo Bastiaens aims to establish a detailed analysis of the impact of international assistance goals and strategies that underscore an evolution of policy reforms and establish patterns of seeming convergence of higher education systems on a global level, while perhaps failing to attend to the local contexts. While research is limited to the Indonesian context, the author explores global investigations of the ambiguous nature of relationships between international assistance and institutional university autonomy, specifically financial autonomy, using sources from other countries as a framework toward examining state-university relationships.

Grounded in Lene Buchert's conceptual classification of education aid policies, this case study examines four types of policies that focus on economic growth as opposed to social welfare. In addition, Jeffrey L. Pressman's aid-giving model and Kristian Kreiner's adaptation of that model explains the impact of organization objectives on the given environments, which in turn is inevitably impacted by the interests of the given organization (i.e., banking and development assistance for the World Bank).

By distinguishing between environments, specifically resource and project environments, this study seeks to avoid the notion that donor aid is purely about education, without taking the environments into account. In addition, Daniel C. Levy explains that the suggested idea of autonomy is conceptualized as the ability of an institution to play a powerful role in resource allocation and make critical decisions that impact the relationships between stakeholders. Bastiaens argues for the use of autonomy, acknowledging external influences and not allowing for absolute reform, but rather for a conceptualization that acknowledges external and internal influences from an institutional perspective. 
Bastiaens uses the higher education system in Indonesia to explore two international assistance programs and their impact on those aspects of environment and autonomy. Specifically, how the goals, efforts, and outcomes of international assistance impact the increased autonomy of universities, evolving from a departure from the current state-centralized education system in Indonesia. Content analysis of documents and interviews with stakeholders provided the framework to draw conclusions to answer the research questions, seeking to understand the multifaceted impacts of international assistance. Data collection and analysis from the two case studies, the World Bank and Dutch Aid, explores the evolution of the Indonesian education system and the complexity of donor-state-university expectations and outcomes of the goals and efforts established by the two cases examined.

Exploring the political context and conditions in Indonesia, themes arose to support the argument toward the potential efficacy of international assistance in higher education as an instrument toward institutional change. While trends in research indicate outcomes critical of the impact of international assistance, the author argues that, in the case of Indonesian higher education, there is evidence to support the argument toward the value of international assistance.

By analyzing the specific qualities of the two case studies, the author's results indicate a complex relationship between the government and universities in Indonesia, which is further complicated by the goals and efforts of international donors. The restructuring of universities in Indonesia to create institutional change and government policy reform is supported by donors, each with their own motivation for a decentralized higher education system.

The goals and efforts of both organizations operate within the political framework of the stateuniversity relations, and reforms tend to indicate that while there is structural weakness and lack of successful implementation of donor goals, there are results that indicate success when domestic reformers and universities make efforts to work with international agencies to enhance autonomy.
Government agenda indicates a bureaucratic pluralism rooted in political and economic ideologies. The evolution of bureaucratic polity in higher education has been significantly impacted by international assistance goals, which provide a framework for decentralization through fiscal independence. While Dutch Aid goals are centered around educational partnerships, the World Bank had more specific agenda regarding economic development and the role of higher education as a way to enhance their broad goals of expanding their lending portfolio and expand their presence in the rapidly growing country. While the government centralized education system promotes political agenda through a high stake in educational reforms, international donor effects are shown to have a contextually significant impact on the increased autonomy of universities.

While the efforts of the two donors in this study are rooted in goals not necessarily complimentary, their outcomes reflect a common thread seen in the Indonesian context as increasing the diversification of resources and redistribute domestic capacities at the state-university level that would not have been achieved without external assistance.

Whether the focus of reform goals focus on staff development and academics (Dutch Aid) or the domestic resource allocation process (World Bank), both approaches catalyzed the move toward external resources, thus enhancing opportunities for university autonomy. The author clearly indicates the movement within the Indonesian higher education system to increased autonomy, especially financial autonomy, has significant obstacles to overcome. Yet, the state-university-donor relationship can be reformed to comply with the needs of all stakeholders by increasing fiscal autonomy for universities through partnerships with the state and international donors to increase the quality and efficiency of the higher education system in Indonesia.

Reviewed by Whitney Szmodis and Sothy Eng Lehigh University, USA 